\title{
Postmetaphysical Conundrums: The Problematic Return to Metaphysics in Horkheimer's Critique of Instrumental Reason
}

\section{George W. Shea, IV}

Largely overshadowed by the renown of his colleagues Theodor W. Adorno, Walter Benjamin, and Herbert Marcuse, Max Horkheimer's contributions to the Frankfurt School are often downplayed as those of the mere director of the Institute for Social Research and the lesser coauthor of Dialectic of Enlightenment. Despite occupying this position of marginality within the corpus of Critical Theory, Horkheimer's work stands as a significant and sustained attempt to develop an interdisciplinary and materialist research program as a methodological alternative to metaphysical philosophy. As J. C. Berendzen notes, one of Horkheimer's most significant contributions to philosophy is his development of materialism as a viable postmetaphysical critical social theory. ${ }^{1}$ Likewise,

I would like to thank the Faculty Research Grant Committee at Misericordia University for the time they afforded me to complete this project. Additionally, I would like to thank Richard Westerman and Martin Niederauer from the Tenth International Critical Theory Conference of Rome for their comments on an early, nascent draft of this article. I would also like to thank Patrick Reider, Melanie Shepherd, James Swindal, and Ryan Watson for their comments on the first full draft. Lastly, I would like to thank an anonymous reviewer at New German Critique whose expertise and insightful feedback helped develop this article into its current form and whose generosity and thoughtfulness will stand as a model of professionalism and collegiality for me in my research, teaching, and service.

1. Berendzen, "Postmetaphysical Thinking or Refusal of Thought?" While Horkheimer himself never used the term postmetaphysical to refer to his work or that of the Frankfurt School, instead generally referring to their philosophical orientation as materialism or Critical Theory, I regard Horkheimer as 
Hauke Brunkhorst lauds Horkheimer's "materialist destruction of philosophy" for opening the way to a "social-scientific transformation of philosophy" that takes leave of the problems of metaphysical philosophy. ${ }^{2}$ Even with such high praise for the strides his early work makes in establishing a tenable materialist, postmetaphysical philosophy, critics such as Georg Lohmann regard Horkheimer's later critique of instrumental reason as engaging in a totalizing critique that undermines its own foundations, which raises once again the question of the precise role metaphysics plays not only in Horkheimer's work but also in critique generally. In his essay "The Failure of Self-Realization: An Interpretation of Horkheimer's Eclipse of Reason, ${ }^{33}$ written expressly for the 1993 collection of essays, On Max Horkheimer: New Perspectives-which aimed to rectify the dearth of attention to Horkheimer's work but is, however, composed of critical essays in concert with Jürgen Habermas's characterization of the failures of Horkheimer's Critical Theory ${ }^{4}$ _Lohmann argues that Horkheimer's narration of the rise of instrumental reason presents the end of metaphysics through an indictment of instrumental reason that must itself in some way rest on a metaphysical foundation if it is to justify its denunciatory claims. For Lohmann, this leaves Horkheimer in an untenable bind: either his critique rests on a metaphysical basis and thereby refutes his very narration of the rise of instrumental reason and the concomitant end of metaphysics, or his critique is without basis and expresses little more than a whimsical resistance to the surge of an increasingly rampant cultural nihilism. Either way, for Lohmann, Horkheimer's position is fraught with aporia. ${ }^{5}$

a member of a loose-knit cadre of thinkers who refuse the blackmail of metaphysics and seek viable theoretical alternatives. Though Horkheimer is self-avowedly a "materialist," his attempt to construct an interdisciplinary materialist research program that would serve as a coherent alternative to metaphysical philosophy speaks to the larger issues that face postmetaphysical philosophies in general.

2. Brunkhorst, "Dialectical Positivism of Happiness."

3. Lohmann, "Failure of Self-Realization" (hereafter cited as FSR). Since Lohmann's essay is one of the few in English to focus exclusively on Eclipse of Reason, it is a primary point of departure for grappling with the complexities and challenges of this text.

4. This dearth continues, as only one major monograph on Horkheimer has appeared in English in the past twenty-five years, John Abromeit's Max Horkheimer and the Foundations of the Frankfurt School, and there is equally a paucity of articles devoted to him. Thus a subsidiary aim of this article is to treat Horkheimer's work in its own right, insofar as it can contribute to our understanding of the issues facing postmetaphysical philosophy in the present.

5. Lohmann's argument here is reminiscent of the well-known critique Habermas in The Philosophical Discourse of Modernity levels at Dialectic of Enlightenment, charging Horkheimer and Adorno with advancing a critique of reason that undermines its own foundations, that is, a "totalizing critique of reason." However, Horkheimer's Eclipse of Reason deserves to be regarded as distinct from Dialectic of Enlightenment for two important reasons. First, it offers a considered and developed solution to the crisis 
While Lohmann states that his overall aim in rereading Eclipse of Reason is to undertake the magnanimous task of rescuing the "critical intent" at work in it (FSR, 388), his reading fails to register a level of nuance vital to Horkheimer's argument. I contend that Horkheimer indeed grounds his indictment of instrumental reason in forms of truth and reason. However, since Horkheimer locates the forms of truth and reason to which he appeals in the nature of nonidentity thinking, he assumes that he has circumvented the trappings of metaphysical philosophy. In this way, Horkheimer both anticipates and evades Lohmann's dilemma. Yet this evasion, I maintain, leaves Horkheimer no better situated, as his position hypostasizes nonidentity thinking and in so doing establishes itself as an antimetaphysical philosophy, which is, simply, another variant of metaphysics. This conclusion though, in and of itself, still leaves us on the welltrod ground of Habermasian and post-Habermasian criticisms leveled against the critique of instrumental reason. Thus I further argue that what is most significant about Horkheimer's establishment of a metaphysical philosophy in this case is not that it merely stands as another instance of "totalizing critique" but, more important, that it also violates the earlier methodological parameters he established for his interdisciplinary materialism as a postmetaphysical philosophy. This is disastrous for Horkheimer, since, as a materialist and postmetaphysical philosopher, he is committed to the position that metaphysics is both an obstacle to the alleviation of human suffering and an instrument of domination. By unwittingly lapsing into metaphysics, Horkheimer's critique of instrumental reason succumbs to the very tyranny and domination it sought to obviate and undermines the original emancipatory purposes of his work. I aim to use the foundering of Horkheimer's critique of instrumental reason on an unintentional lapse into metaphysical philosophy to signal the perils that lie in wait for any postmetaphysical philosophy that fails to steer a clear path between the antipodes of metaphysical and antimetaphysical positions.

I turn first to Horkheimer's materialist essays of the 1930s in which he sketches out his conception of, and objections to, metaphysics as well as how his conception of an interdisciplinary materialism offers an alternative to the transhistorical project of metaphysical philosophy. Next, I examine the place of metaphysics in the critique of instrumental reason as it is elaborated in Eclipse of Reason. I revisit Lohmann's critique of Horkheimer to demonstrate that through the hypostatization of nonidentity thinking, which he intends to serve

of instrumental reason, a solution Dialectic of Enlightenment only vaguely intimates. Second, and central to this article, it ties the crisis of instrumental reason explicitly and directly to the project of Western metaphysics, unlike Dialectic of Enlightenment. 
as a basis for the critique of instrumental reason, Horkheimer unwittingly establishes a transhistorical antimetaphysical philosophy that runs counter to his own aims. Lastly, I articulate the manner in which this perilous move calls on postmetaphysical philosophies to renounce conventional metaphysical foundationsboth ontologically and normatively - if they are to avoid the incoherencies and contradictions of antimetaphysical positions.

\section{Interdisciplinary Materialism and Metaphysics}

According to Horkheimer, metaphysics, as classically conceived, is concerned with securing an absolutely perfect understanding of ultimate reality. Traditionally, this is understood in terms of the inquiring subject trying to discern with perfect clarity the fundamentally unified and universal structure of reality that underlies the totality of being. As a consequence, a central component of metaphysical thinking, and the epistemological position that it assumes, is the tendency to pursue an ideal correspondence between knowledge and the known-or rather, an identity between the concept of the object and the object of the concept. In this way, the knowledge of the knowing subject and the fundamental structure of reality should perfectly coincide.

More significantly, Horkheimer claims that metaphysicians engage in the project of metaphysics not merely for its own sake but also out of a desire to provide an absolutely certain foundation for normativity. As Horkheimer notes:

\footnotetext{
The effort to make his personal life dependent at every point on insight into the ultimate ground of things marks the metaphysician. ${ }^{6}$

The metaphysician thus believes that, in the being he seeks to discover, a basis may be found for shaping the individual's life. . . Ultimate reality is regarded as normative, however, not only in those systems where religious origins of the dependence relationship still show in the form which precept takes, but also in all cases where harmony between the individual's existence and its ground as discovered by metaphysics is regarded as valuable. (MM, 18-19)
}

For Horkheimer, one of the hallmarks of metaphysical thinking is an attempt to ground both ethics and a basis for normative critique in an understanding of ultimate reality.

Horkheimer, however, has two objections to the project of metaphysics. First, he claims that the task of trying to ascertain the fundamental structure of 
reality turns us away from the problems of this world and focuses us instead on another, and quite possibly illusory, world. This, in effect, cultivates an insensitivity to the wretchedness of the world and our time, and distracts us from seeking its causes and altering its conditions. Rather than place a higher value on changing the immediate and concrete material conditions of human existence in this world, metaphysics relegates the social problems of this world to an inferior position relative to the project of absolute knowing. Consequently, for Horkheimer, the task of metaphysics by its very nature devalues human existence in favor of another world and thereby ignores the plight of humanity. Second, and more important, Horkheimer claims that, under the guise of universality, metaphysical theories have been employed throughout history as a way to justify the demand to recognize what are merely the particular interests of individuals and social groups. As Horkheimer states: "Ruling and ruled classes alike have not been satisfied to present their claims simply as expressions of their particular needs and desires. They have also proclaimed them as universally binding requirements grounded in transcendent sources, as principles in accord with the eternal nature of the world and man" (MM, 22). In other words, social classes are rarely content to present their specific needs as an expression of their own personal agenda and instead often present those needs as universal and binding laws of nature. For this reason, Horkheimer characterizes metaphysics as an instrument of domination-that is, as a method for imposing one's own interests on others and for soliciting their obedience in the process of doing so.

Critically suspicious of the project of metaphysics, Horkheimer casts doubt on the very possibility of procuring a cognition of the eternal and unchanging structure of ultimate reality, arguing that

\begin{abstract}
the claim that there is an absolute order and an absolute demand made upon man always supposes a claim to know the whole, the totality of things, the infinite. But if our knowledge is in fact not yet final, if there is an irreducible tension between concept and being, then no proposition can claim the dignity of perfect knowledge. Knowledge of the infinite must itself be infinite, and a knowledge which is admittedly imperfect is not a knowledge of the absolute. (MM, 27)
\end{abstract}

For Horkheimer, the project of metaphysics problematically assumes an eternal and unchanging structure of reality as well as a knowing subject that can, through reason, transcend the particularities and specificities of space and time to access this essential structure. In other words, Horkheimer understands metaphysics as a transhistorical project aiming to secure what is unconditioned. 
However, such a project seems infeasible to Horkheimer. Neither nature nor the subject appears to possess the immutability attributed to them by metaphysics. Instead, advancing his interdisciplinary materialism as a methodological alternative to metaphysics, Horkheimer operates with a conception of the knowing subject as deeply situated within its historical and material conditions and as thereby constituted by those conditions.

The methodological difference between Horkheimer's interdisciplinary materialism and metaphysics is here worth emphasizing. Whereas metaphysical philosophies advance absolute and universal claims about both the knowing subject and reality, the position advanced by an interdisciplinary materialism concerning the knowing subject and reality is not regarded as claims about the timeless and enduring nature of either but is instead explicitly held as hypothetical and provisional principles postulated for understanding our historical moment as well as for guiding and orienting inquiry. The importance of understanding Horkheimer's interdisciplinary materialism distinctly as a method, to distinguish it from metaphysics, is similarly emphasized by Brunkhorst:

\begin{abstract}
The other limit is the historicity of real subjects. Entirely in the sense of historicism, the contingent historical horizon of the "respective concrete situation of the actor" is an insuperable given for them. Everything is historically conditioned. Nor is that meant as transcendental philosophy: it is only a refutable supposition, which has taken its leave of philosophy. Therefore . . Horkheimer's materialism is essentially methodological materialism. It has a decidedly scientistic streak. It accepts the distinction between "is" and "ought." Fallibilistic and oriented toward the sciences of experience, this materialism seeks to expose its own hopes to disillusionment. Along with Dilthey, it regards metaphysics as a mere hypothesis. It is a resolute attempt at a transformation of philosophy into science but not simply in order to have the specialized disciplines step into the place of philosophy. Methodological materialism takes the primacy of experience as its point of departure. ${ }^{7}$
\end{abstract}

There are two primary reasons for emphasizing this methodological difference between Horkheimer's interdisciplinary materialism and metaphysics. The first involves the potentially self-referential and ultimately contradictory nature of the position Horkheimer must avoid. If he were to posit the historically conditioned nature of both the knowing subject and the world as absolutes or as reflecting the inherent and timeless nature of things, then his position would immediately lapse into a variant of metaphysics - that is, Horkheimer's interdisciplinary materialism would be guilty of engaging in the very same transhistorical project of which

7. Brunkhorst, "Dialectical Positivism of Happiness," 78-79; emphasis added. 
he charges metaphysics and would, of necessity, undermine itself. ${ }^{8}$ As his essays from the 1930s demonstrate, Horkheimer takes considerable pains to distinguish between his position and that of metaphysics. The second reason is that understanding Horkheimer's interdisciplinary materialism as a method-as selfreflexively hypothetical and provisional—similarly helps guard against the dogmatic tendencies inherent in metaphysics, tendencies Horkheimer is explicitly interested in avoiding. In this precise connection, Horkheimer notes, "Throughout its history materialism has held to this theory of knowledge [relying on sense experience], which serves as a critical weapon against dogmatism" (MM, 42). Thus the principles and concepts advanced by Horkheimer, if they are to refrain from transforming into transhistorical and absolutist dogma, must maintain a self-reflexively hypothetical and provisional status.

Given, however, that Horkheimer's interdisciplinary materialism rejects metaphysical absolutes for historically conditioned subjects and objects, it would seem that his interdisciplinary materialism runs the risk of being little more than either a form of skepticism or a form of relativism. If we cannot know truth absolutely, or an absolute truth, then it would appear that we are unmoored from any means by which to determine the validity of concepts. Yet, anticipating such criticisms, Horkheimer asks, "Is there really only a choice between acceptance of a final truth, as proclaimed in religious and idealistic schools of philosophy, and the view that every thesis and every theory is always merely 'subjective,' i.e., true and valid for a person or group or a time or human beings as a species, but lacking objective validity?"9 This dilemma, for Horkheimer, is a false one. Explicitly rejecting both skepticism and relativism, Horkheimer characterizes his interdisciplinary materialism as an alternative to both the naivete of the metaphysics of truth and the absurdities of an academic, and relativistic, skepticism.

First, in Horkheimer's estimation, G. W. F. Hegel satisfactorily addresses philosophical skepticism via the notion of "determinate negation" (OPT, 184). A skeptic would argue that because a series of concepts can never represent an object accurately, the project of knowing is inherently flawed and ill-fated from its very inception. Hegel, however, argues that the series itself is a process of increasingly accurate depictions of the object and not a series of failures. When an element of an object invalidates our concept of that object, we do not simply abandon the concept tout court; the negation of the concept is not absolute. In other words, a "determinate negation" is not a disjunction in which the

8. This is, in essence, what I argue occurs in Horkheimer's later critique of instrumental reason.

9. Horkheimer, "On the Problem of Truth," 183 (hereafter cited as OPT). 
book is on the shelf or the book is not on the shelf. Rather, the negation of the concept is specific, playing a determinate part in the construction of the new concept. ${ }^{10}$ For Horkheimer, Hegel's concept of "determinate negation" militates against skepticism.

Yet, in Horkheimer's estimation, we must move past Hegel, since he remains caged within idealistic, dogmatic, and metaphysical philosophy. For Hegel, "The goal is as necessarily fixed for knowledge as the serial progression; it is the point where knowledge no longer needs to go beyond itself, where knowledge finds itself, where Notion corresponds to object and object to Notion." ${ }^{11}$ In this way, according to Horkheimer, just as Kant's theory of knowledge succumbs to Hegel's critique, so Hegel's critique of Kant succumbs to Karl Marx's:

[In] contemplating his own system, Hegel forgets one very definite side of the empirical situation. The belief that this system is the completion of truth hides from him the significance of the temporally conditioned interest which plays a role in the details of the dialectical presentation through the direction of thought, the choice of material content, and the use of names and words, and diverts attention from the fact that his conscious and unconscious partisanship in regard to the problems of life must necessarily have its effect as a constituent element of his philosophy. (OPT, 187)

In other words, Hegel disregards the historically conditioned character of thought and succumbs to Marx's claim that all thought is conditioned by its time (OPT, 186).

Consequently, whereas Hegel advocates a closed dialectic that will one day resolve itself in absolute knowing, Horkheimer advocates an open dialectic:

The open-ended materialistic dialectic does not regard the "rational" as completed at any point in history and does not expect to bring about the resolution of contradictions and tensions, the end of the historic dynamic, by the full development of mere ideas and their simple consequences. It lacks the aspect of the idealistic dialectic that Hegel described as "speculative" and at the same time as "mystical," namely, the idea of knowing the ostensibly unconditioned and thereby being oneself unconditioned. (OPT, 209-10)

10. Using the US 2012 presidential race as an example, the Republican Party avowedly had a poor concept of the American voting constituency. This was manifested in the extreme disjunction between the election results the party anticipated and the actual results. This discrepancy forced the Republican Party to reexamine its initial concept. Although this concept is not negated absolutely, it is negated in a significant way: the inadequacies in the original concept point toward a more adequate concept.

11. Hegel, Phenomenology of Spirit, 51. 
Instead, for Horkheimer, "materialism . . . maintains the irreducible tension between concept and object and thus has a critical weapon of defense against belief in the infinity of the mind" (MM, 28).

Second, materialism's rejection of a metaphysical absolute does not entail that a measure for truth cannot be established and that it is therefore a form of relativism. As in the sciences, generally accepted criteria—or, in Horkheimer's words, "available means of cognition" (OPT, 192, 203)—are in place at any given time for determining the truth value of propositions. Horkheimer appeals to the example of medicine. Thus we might say that while the concept of cancer may change over time and eventually become meaningless as we currently understand it, it has a precise meaning in our present, and only one of two conflicting claims as to the presence of cancer in a patient will be correct. As Horkheimer states, "Truth is decided not by individual's beliefs and opinions, not by the subject in itself, but by the relation of the proposition to reality" (OPT, 194). In this way, there is a generally accepted body of knowledge and a rigorous method for establishing truth, and one either correctly or incorrectly appeals to and applies these. "From this follows the principle that every insight is to be regarded as true only in connection with the whole body of theory, and hence is so to be understood conceptually that in its formulation the connection with the structural principles and practical tendencies governing theory is preserved" (OPT, 204). In other words, while on the particular level of specific instances of cancer, one either diagnoses correctly or incorrectly; when the very concept of cancer is called into question, this itself takes place in the greater context of a theoretical framework and will have to resolve itself within this framework. Here Horkheimer is accounting for what we might today call a "paradigm shift" within a specific discipline ${ }^{12}$ or a discursive rupture. ${ }^{13}$ Concepts and theories can indeed be brought into play that call into question the entire body of knowledge heretofore regarded as established in a discipline-for example, the Einsteinian reframing of Newtonian mechanics or our understanding of disease. Yet these debates themselves take place in the context of a greater theoretical framework, in the context of methods and aims that superseded and directed the very nature of those debates.

Quite clearly, Horkheimer is affirming a combination of the correspondence theory of truth and a coherence theory of truth, holding these as staving off the difficulties of skepticism and relativism. ${ }^{14}$ Yet, rather than naively

12. See Kuhn, Structure of Scientific Revolutions.

13. See Foucault, History of Madness, Birth of the Clinic, or Order of Things.

14. It is beyond the scope of this article to assess the intricacies of Horkheimer's epistemology. Rather, my aim is to highlight the fact that developing a nonmetaphysical epistemology was an explicit component of Horkheimer's interdisciplinary and materialist research program. 
thinking that either reaches the unconditioned, Horkheimer emphasizes the historically conditioned character of the knower, her tasks, and what she seeks to understand. Thus theory is always related to sociohistorical practice, even those theories that, on the surface, appear most theoretically abstract. In this way, while there is no "absolute knowing" for Horkheimer, not all claims to truth are equally valid. Within the generally accepted parameters of knowledge at a given time, there are criteria and methods for distinguishing true claims from false claims, even if those claims once held true may one day prove to be false from a refined and newly established understanding. So Horkheimer can confidently claim:

\footnotetext{
Recognition of the conditional character of every isolated view and rejection of its absolute claim to truth does not destroy this conditional knowledge; rather, it is incorporated into the system of truth at any given time as a conditional, one-sided, and isolated view. Through nothing but this continuous delimitation and correction of partial truths, the process itself evolves its proper content as knowledge of limited insights in their limits and connection. (OPT, 184)
}

In this connection, we here return to the Frankfurt School's Marxist roots. For Horkheimer, what clearly distinguishes his interdisciplinary materialism from metaphysics, skepticism, relativism, or science is that it deliberately aims to understand the current forms of social domination that arise under the capitalist mode of production so as to change them. In other words, the "need to comprehend contemporary society" calls for an "economic theory of society" (MM, 45). Nor should this be understood in a narrow and reductive sense, as Horkheimer's interdisciplinary materialism has, since its inception, drawn on psychoanalysis and empirical social research to understand "the connection between the economic life of society, the psychical development of individuals, and the changes in the realm of culture in the narrow sense." ${ }^{15}$ Since the very object of inquiry for an interdisciplinary materialism is highly mobile and fluid - society is a multifaceted, complex, and dynamic phenomenon-an interdisciplinary materialism must of necessity take into account not only the fluidity of its object but also the necessity of remaining adaptable in its concepts. As Horkheimer says elsewhere, "The various materialist doctrines, therefore, are not examples of a stable and permanent idea" (MM, 45). Thus an interdisciplinary materialism rejects transhistorical metaphysical theories 
of the unconditioned and opts instead for the mutability of understanding produced through an open dialectic. Stating the benefit of the open materialistic dialectic, Horkheimer claims:

By ceasing to be a closed system, dialectic does not lose the stamp of truth. In fact, the disclosure of conditional and one-sided aspects of others' thought and of one's own constitutes an important part of the intellectual process. Hegel and his materialist followers were correct in always stressing that this critical and relativizing characteristic is a necessary part of cognition. But being certain of one's own conviction and acting upon it do not require the assertion that the concept and object are now one, and thought can rest. To the degree that the knowledge gained from perception and inference, methodical inquiry and historical events, daily work and political struggle, meets the test of the available means of cognition, it is the truth. The abstract proposition that once a critique is justified from its own standpoint it will show itself open to correction expresses itself for the materialists not in liberality toward opposing views or skeptical indecision, but in alertness to their own errors and flexibility in thought. (OPT, 191-92)

As should now be evident, an interdisciplinary materialism operates wholly outside the confines of a project that occupies itself with securing the unconditioned. Instead, Horkheimer's interdisciplinary materialism abandons the old paradigm of measuring its concepts against the ideal of absolute knowing: "Since that extra-historical and hence exaggerated concept of truth is impossible, which stems from the idea of a pure infinite mind and thus in the last analysis from the concept of God, it no longer makes sense to orient the knowledge that we have to this impossibility and call it relative" (OPT, 192). Rather, as noted above, an interdisciplinary materialism moves closer to the methods and practices of science without reducing itself to them. ${ }^{16}$ Hence an

16. As Horkheimer himself notes: "The relationship between philosophical and corresponding specialized scientific disciplines cannot be conceived as though philosophy deals with the really decisive problems - in the process constructing theories beyond the reach of the empirical sciences, its own concepts of reality, and systems comprehending the totality - while on the other side empirical research carries out its long, boring, individual studies that split up into a thousand partial questions, culminating in a chaos of countless enclaves of specialists. This conception-according to which the individual researcher must view philosophy as a perhaps pleasant but scientifically fruitless enterprise (because not subject to experimental control), while philosophers, by contrast, are emancipated from the individual researcher because they think they cannot wait for the latter before announcing their wide-ranging conclusions - is currently being supplanted by the idea of a continuous, dialectical penetration and development of philosophical theory and specialized scientific praxis. . . . In short, the task is to do what all true researchers have always done: namely to pursue their larger philosophical questions on the basis of the most precise scientific methods, to revise and refine their questions in the course of 
interdisciplinary materialism uses concepts as hypotheses formulated on the basis of the best and most rigorously accumulated knowledge at the time, but it holds those concepts open to revision and continual scrutiny, guided always by the concern to ameliorate the material and historical conditions of suffering in contemporary society. ${ }^{17}$ As Brunkhorst characterizes it, "The most general fundamental principles of the materialists-constitution-theoretical, even ontological-sounding theses such that 'all that exists is material'-have a merely hypothetical status, dependent of fallible experience." ${ }^{18}$ Again, this is not to suggest a retreat into either relativism or nihilism. Rather, it is an attempt to advance a method for determining the most adequate theory of the current historical condition while remaining open to the dynamic nature of the objects of inquiry and the requirement to remain flexible in the need to adjust theory. Unlike metaphysical philosophies, which take themselves to be the one and only true form of inquiry, interdisciplinary materialism employs the open dialectic to remain vigilant against dogmatism while remaining open to amending its conceptual formulations.

Even more significant, since an interdisciplinary materialism indeed operates outside the confines of the traditional project of metaphysics, it also therefore rejects the notion of a metaphysically grounded normative position of action or critique. Horkheimer further elaborates this position in his essay "Materialism and Morality." There he again casts metaphysics as concerned with securing absolute moral principles: "As distinctive as the systems of Leibniz, Spinoza, and the Enlightenment may be, they all bear the marks of an effort to use the eternal constitution of the world and of the individual as the basis for establishing some determinate manner of conduct as being appropriate for all time. They therefore make a claim to unconditional validity." ${ }^{19} \mathrm{He}$ similarly rejects such attempts: "Morality does not admit of any groundingneither by means of intuition nor of argument." ${ }^{20}$ Instead, under Horkheimer's conception, an interdisciplinary materialism aims to reveal and understand how moral systems reflect the sociohistorical conditions from which they arise. For Horkheimer, "Materialism sees in morality an expression of life of determinate individuals and seeks to understand it in terms of the conditions of

their substantive work, and to develop new methods without losing sight of the larger context" ("Present Situation of Social Philosophy," 8-9).

17. The latter aim marks one of the fundamental differences later for Horkheimer between traditional and Critical Theory. See "Traditional and Critical Theory," 198-99 (hereafter cited as TCT).

18. Brunkhorst, "Dialectical Positivism of Happiness," 77.

19. Horkheimer, "Materialism and Morality," 16.

20. Horkheimer, "Materialism and Morality," 33. 
its emergence and passing, not for the sake of truth in itself but rather in connection with determinate historical forces." ${ }^{21}$ Horkheimer aims to demonstrate how the Kantian moral system, with its emphasis on a disinterested accord with duty, reflects economic and social relations under capitalism. Significantly, however, he is quite clear that his interdisciplinary materialism bars methodologically the possibility of providing an absolute foundation for morality itself. Horkheimer openly admits that an interdisciplinary materialism is without a traditional ground for its moral and normative position: "This materialist view has the negative significance that it rejects a metaphysically grounded morality" (MM, 44). Nonetheless, an interdisciplinary materialism is not a form of quietism: "It has always meant to materialists that man's striving for happiness is to be recognized as a natural fact requiring no justification" (MM, 44). At its core, interdisciplinary materialism, then, refuses to postpone changing this world in favor of theorizing about another. And, in keeping with the historically conditioned character of both subjects and objects, Horkheimer further contends:

\begin{abstract}
Politics in accord with this goal [the ideals of freedom, equality, and justice] therefore must not abandon these demands, but realize them-not, however, by clinging in a utopian manner to definitions which are historically conditioned, but in accordance with their meaning. The content of the ideas is not eternal, but is subject to historical change-surely not because "Spirit" of itself capriciously infringes upon the principle of identity, but because human impulses which demand something better take different forms according to the historical material with which they have to work.
\end{abstract}

Again, the guiding aim of an interdisciplinary materialism is to alter the material conditions of this world in which people suffer and to develop a theoretical position that can most effectively realize this aim. More precisely, we find since at least the start of the twentieth century a disproportionate amount of suffering that is due to a deficiency neither in resources nor in technology, since both exist in such abundance as to provide a reasonable quality of life for all. Rather, for Horkheimer, the current state of inequality and barbarism is the result of our economic situation, with capitalism as the dominant mode of production. The goal for an interdisciplinary materialism is to develop a theory of society that ameliorates the suffering of the majority of people in this world rather than finding a reason to do so in another. In the words of John Abromeit, "Critical 
Theory is ultimately driven by the interests of concrete individuals in a better life, not by its own perfect knowledge of the social totality or privileged insight into a utopian blueprint of a better society." 22 Significantly, then, rather than attempt to gain an insight into the ultimate nature of reality, interdisciplinary materialists aim to formulate dialectical conceptions of sociohistorical formations so that they can direct those formations toward the fulfillment of human satisfaction.

\section{From an Interdisciplinary Materialism to the Critique of Instrumental Reason}

As previously mentioned, Horkheimer's interdisciplinary materialism has "society itself as its object" (TCT, 206). However, it is society not as a disinterested object of contemplation but as an object of deep concern born out of a vested interest in establishing "a rationally organized future society" for "radically improving human existence" (TCT, 233). This self-reflexive interest in transforming the object of its inquiry, as opposed to a purported impartiality, is a distinguishing characteristic, for Horkheimer, between Critical Theory and traditional theory — between, respectively, Horkheimer's own interdisciplinary materialism and those theoretical approaches from which he differentiates it. In essence, traditional theory stands as the culmination of the metaphysical and epistemic ideals of early modernity that privilege the model of an abstract and disembodied knowing subject underpinning a systematic, unified, and comprehensive theoretical totality and provides the basis for a universal and complete science of all possible objects. At issue in the difference between the two approaches to theory, for Horkheimer, is the relationship between theory and praxis. ${ }^{23}$ According to Horkheimer, the abstract and disembodied epistemic subject of traditional theory comes to represent the subject itself and, in doing so, valorizes and produces an apolitical and individualized monadic social subject. On this basis, Horkheimer argues that "traditional theory" is responsible for constructing and disseminating a conception of the subject as an autonomous and disinterested spectator, whose interests are unaffected by the conditions in which the subject finds itself. Thus the abstract knowing subject, concretized in the form of the Cartesian subject, metastasizes into a monadic social entity untouched by the exigencies of social life, which propagates an image of the subject as the ground of its own values and not as a product of sociohistorical forces. In this way, the monadic individual operates with a "distorted"

22. Abromeit, Max Horkheimer, 329.

23. Abromeit, Max Horkheimer, 321-35. 
sense of freedom and autonomy, since it identifies with itself as an abstract rather than as a historical and material entity and fails to recognize itself as the product of, and an agent of, social change, which results in the abdication of its responsibility for producing the very conditions of its social existence. In distinction to traditional theory, Critical Theory fully embraces the dialectical character of both its historically and materially conditioned motivations as well as its objects of inquiry and their conceptual formulations. In this way, Critical Theory serves self-reflexively as a transformative activity that brings together both theory and praxis.

By the 1940s, however, guided by a lifelong commitment to identifying the causes of suffering and working toward mitigating their effects, ${ }^{24}$ and having identified the hypostatized knowing subject as the cause of the socially disengaged monadic subject, Horkheimer turns to tracing the historical origins of what he elsewhere calls the "Cartesian-empiricist philosophy of consciousness." ${ }^{25}$ Since Horkheimer's interdisciplinary materialism begins with the principle that all thinking is historically and materially conditioned, the critique of instrumental reason is not a complete break in critical method, or even a total shift in critical object, but a continued development of the critique of the metaphysical and epistemic subject of traditional theory carried out under the earlier aegis of "Critical Theory." ${ }^{26}$ Having identified the schematic form of the ills of our time - a socially disengaged monadic subject—a diagnostic task of Horkheimer's middle period becomes to trace the conditions of this form of subjectivity back to its genesis so that the causes of suffering in our own time might be corrected and an alternative path for humanity might be identified. ${ }^{27}$

Dialectic of Enlightenment, written with Adorno, partly undertakes this task. However, while Dialectic of Enlightenment indeed focuses on a historical analysis of the origin and rise of the modern scientific attitude — culminating in

24. A defining aim of Horkheimer's oeuvre is to identify the sources of suffering in the contemporary world so as to alleviate them. This motif is present in Horkheimer's earliest writing, Dämmerung, and continues up until his last essays, such as "Threats to Freedom" and "The Future of Marriage."

25. Horkheimer, "Rationalism Debate in Contemporary Philosophy," 220.

26. Martin Jay argues that Horkheimer's "Beginnings of the Bourgeois Philosophy of History" is a paradigmatic example of this continuity in the oeuvre of Horkheimer (Dialectical Imagination, 257).

27. My aim here is not to contest the established shift that occurs in Horkheimer's thought from the 1930 s to the 1940 s but simply to note that the metaphysical and epistemic subject of early modernity remained an abiding concern of Horkheimer's even if treated in varied forms. The personal, intellectual, and social factors contributing to the shifts in Horkheimer's thinking, as well as that of the other members of the Frankfurt School, are too numerous to mention here. For accounts of these shifts, see the excellent works by Abromeit, Susan Buck-Morss, Helmut Dubiel, Martin Jay, Stuart Jefferies, Peter M. R. Stirk, and Rolf Wiggershaus. 
the instrumentalization of reason — and holds out the vague hope for a form of reason that is "other" to it, its analyses remain hastily sketched and only partially developed, and an explicit discussion of the relationship between metaphysics and instrumental reason is conspicuously missing. In contrast, Eclipse of Reason provides a much fuller and richer historical account of the rise of instrumental reason, there termed subjective reason. While Horkheimer's account of the evolution of Western reason in Eclipse of Reason continues to locate the birth of reason in the drive to self-preservation and the reciprocal impulse to dominate nature, its history now passes through metaphysics. On this account, Western reason finds its first expression in myth, transforms into metaphysics, and ends in science. The significance here is worth noting. Whereas Horkheimer had formerly been quite careful to characterize his interdisciplinary materialism as an alternative to metaphysics and not as refutation of metaphysics, thereby steering clear of the question of the end of metaphysics, here in Eclipse of Reason Horkheimer announces the destruction of Western metaphysics, since, on his account, metaphysics as a speculative enterprise harbors the elements of its own demise at the hands of the empirical sciences to which it gives rise. Thus Horkheimer's critique of instrumental reason fundamentally precludes an appeal to metaphysics as an antidote to what he considers the tyrannical reign of subjective reason.

\section{The Place of Metaphysics in Horkheimer's Critique of Instrumental Reason}

In no uncertain terms, Horkheimer states that the purpose of Eclipse of Reason is "to inquire into the concept of rationality that underlies our contemporary industrial culture in order to discover whether this concept does not contain defects that vitiate it essentially." 28 The concept of reason that concerns Horkheimer here is what he identifies as subjective reason. In its subjective form, reason functions merely as a formal mechanism of classification, inference, and deduction, and, more important, its operations lie entirely in determining and coordinating the most efficient means for already established ends. However, this entails that subjective reason alone is incapable of evaluating the suitability and worth of ends themselves. Instead, this task falls to reason in its objective form. Originating in Greek antiquity as the project of metaphysics, objective reason aims to access and disclose the rational order inherent in the universe that exists independently of individual subjects and provides the measure for 
assessing the reasonableness of one's life and actions, which is typically formulated in terms of either a harmony or discord between one's life and that order.

Since objective reason claims absolute authority over proclamations about the ultimate nature of reality, it exists in tension with mythology and religion, both of which equally make assertions about the eternal order of things and our place within it. Despite this tension, objective reason-as it was resurrected in the Renaissance, developed in the Scientific Revolution, and culminated in the ideals of the Enlightenment - won out over myth and religion as the legitimate source of knowledge and therefore of authority. Yet in the end this victory served only as a step toward objective reason's own destruction. As formalized science progressed, it in turn came to be regarded as having established the singular method for determining truth. Just as objective reason dethroned religion by casting it as irrational myth, so science dethroned metaphysics by casting it as nothing more than idle speculation, and in doing so unmoored human enterprise from an objective foundation. In this connection, Horkheimer notes:

The philosophers of the Enlightenment attacked religion in the name of rea-
son; in the end what they killed was not the church but metaphysics and the
objective concept of reason itself, the source of power of their own efforts.
Reason as an organ for perceiving the true nature of reality and determining
the guiding principles of our lives has come to be regarded as obsolete. Spec-
ulation is synonymous with metaphysics, and metaphysics with mythology
and superstition. We might say that the history of reason or enlightenment
from its beginnings in Greece down to the present has led to a state of affairs
in which even the word reason is suspected of connoting some mythological
entity. Reason has liquidated itself as an agency of ethical, moral, and reli-
gious insight. $(E R, 18)$

In other words, with the rise of scientism during the nineteenth and twentieth centuries, subjective reason comes to supplant objective reason, culminating in a crisis of reason-leaving us without a mechanism by which to determine objectively the suitability of ends themselves. Instead, the determination of goals and values now depends on something other than reason; they become a matter of mere predilection.

What is worse, according to Horkheimer, is that the crisis of reason not only leaves us without a guiding normative principle but also thereby precipitates a tide of global conformity and an accompanying loss of individuality, since, without an objective orientation for thought, reason now serves in its subjective form as a mechanism of adaptation. Now that reason is no longer 
capable of putting forward ideals by which individuals might change the world, instead it operates only in the service of those that have already been established. Moreover, in this situation, self-preservation stands as the only immediately obvious end worth pursuing. When this pursuit is coupled with a socioeconomic environment governed entirely by the logic of profit, the only means of survival available to individuals is to make themselves "useful" within it. Once subjective reason takes hold of economic profit as its exclusive end, individuals engage in totalizing calculations aimed at transforming themselves into economically useful agents. The effect causes individuals to abandon the pursuit of their own self-interest as well as the hope of any form of self-realization other than as subjects of capitalism.

For Horkheimer, this means that individuals no longer realistically consider ways of living that will not in the end produce a "return on investment." We do not seriously consider spending our lives cycling around the world, since this is useful to no one. We do not regard an education as an opportunity to transform ourselves into "better" people capable of more fulfilling lives, since we view education merely as providing the qualifications necessary for appearing employable. If we engage in aesthetic production, the quality of our work is assessed in terms of its salability and not according to some other criteria-just like our lives. Moreover, we are almost certain to wear fashionable clothes, listen to popular music, and watch popular television programs and movies to appear relatively normal, since, in deviating from the norm, we run the risk of exclusion, and those who are excluded diminish their chances of survival. ${ }^{29}$ Ultimately, we adapt to the socioeconomic environment in which we find ourselves, which is accomplished by demonstrating our worth in the marketplace, and the manufacturing of this utility and profitability comes at the cost of having to sacrifice ourselves.

There is a real absurdity and contradiction in this situation for Horkheimer. The very form of reason that was supposed to liberate us from domination and oppression has rebounded to create a condition in which we abandon the pursuit of our own self-interests and self-realization to make ourselves into something "useful" for the production of profit, which is itself directed and determined by the unfettered whims of the free market. In this way, reason now serves as a mechanism that adapts us to the economy of irrationality that governs our lives.

29. The themes of normalization and exclusion are elaborated previously by Horkheimer and Adorno in Dialectic of Enlightenment: "Anyone who does not conform is condemned to an economic impotence which is prolonged in the intellectual powerlessness of the eccentric loner. Disconnected from the mainstream, he is easily convicted of inadequacy" (106). 
For Horkheimer, we find that the Marquis de Sade's imprisoned pleasures have installed themselves as our social nightmare:

\begin{abstract}
It may be just as meaningless to call one particular way of living, one religion, one philosophy better or higher or truer than another. Since ends are no longer determined in the light of reason, it is also impossible to say that one economic or political system, no matter how cruel and despotic, is less reasonable than another. According to formalized reason, despotism, cruelty, oppression are not bad in themselves; no rational agency would endorse a verdict against dictatorship if its sponsors were likely to profit by it. $(E R, 31-32)$
\end{abstract}

At the heart of the problem, for Horkheimer, is the very project of reason itself, which has always aimed at establishing human security and fulfillment through the domination of nature. This project culminates early on in the great metaphysical systems of Western history that valorize the knowing subject as an abstract ego distinct and separate from the external world that it seeks to understand for the purposes of mastering and controlling it. Whether it is the Platonic tripartite soul, the Thomistic eternal soul, the free Cartesian ego, the Kantian transcendental ego, or Hegelian Absolute Spirit, all of metaphysics assumes an abstract ego that distances itself from everything alien to itimpulses, desires, the body, and the world — so as to dominate and subjugate it all the more thoroughly. According to Horkheimer:

\begin{abstract}
It is instructive to follow Descartes' efforts to find a place for this ego, which is not in nature but remains close enough to nature to influence it. Its first concern is to dominate the passions, that is, nature, so far as it makes itself felt in us. The ego is indulgent to agreeable and wholesome emotions but is stern with any conducive to sadness. Its central concern must be to keep the emotions from biasing judgments. Mathematics, crystal-clear, imperturbable, and self-sufficient, the classical instrument of formalized reason, best exemplifies the workings of this austere agency. The ego dominates nature. $(E R, 107)$
\end{abstract}

For Horkheimer, the history of metaphysics, as the history of the abstract ego, is the story of the history of the domination of nature both within and without the subject, since to guarantee the purity of its conceptualizations, which are necessary for dominating nature without, the subject, as the ego, must dominate the corrupting influences of nature-as desire, instinct, and passionwithin. Thus the very project of the domination of nature has always necessarily included the project of the domination of humanity $(E R, 105)$. Yet the project of the domination of nature has not always entailed the total sacrifice and 
liquidation of the individual. In its earliest formations among the ancient Greeks, the project of metaphysics required certain sacrifices on the part of the subject, certain forms of self-control and self-restraint, but they were thought to be in accord with an order that enriched the polis and thereby secured the autonomy and realization of the self $(E R, 131)$. However, now that metaphysics has come to an end, there is no objective order to which we might work to conform in hopes of achieving greater autonomy. Instead, we sacrifice ourselves so as to adapt to the world as it is only in the hope that we may merely survive. The project of dominating nature and realizing human autonomy, which required the domination of the self by the self, has resulted in the total liquidation of the self. Thus Horkheimer concludes, "The theme of this time is self-preservation, while there is no self to preserve" $(E R, 128)$.

Despite the dire tone of his analyses, Horkheimer remarks, "The disease of reason is that reason was born from man's urge to dominate nature, and the 'recovery' depends on insight into the nature of the original disease, not on a cure of the latest symptoms" $(E R, 176)$. In other words, for Horkheimer, all is not lost. Indeed, the very aim of philosophical thinking, on his account, is "to essay a reconciliation" of the antagonism between reason and nature that reason has either forgotten or denies exists $(E R, 162)$. This means developing something other than the metaphysical conception of nature in which this antagonism has manifested itself. At the core of metaphysics, for Horkheimer, is the logic of identity - the attempt to fashion all-encompassing and totalizing concepts from which nothing can escape and for which there is no remainder ( $E R$, 169). As noted above, the epistemic ideal of metaphysical concepts is a perfect equivalence between concept and object. However, these metaphysical concepts presuppose both transhistorical unities that exist independently of the historical contingencies of space and time, and a knowing subject that can overcome those historical contingencies so as to access them. In this way, the metaphysical impulse, which employs the logic of identity, of necessity gives rise to the ideal of an abstract ego that can extricate itself from nature, both within and without, and conceptualize nature accurately. At bottom, the metaphysical impulse pits the abstract ego, as the locus of reason, against nature as if they were two distinct yet somehow related entities. However, for Horkheimer, a real reconciliation between reason and nature via a nonmetaphysical paradigm must take care neither to perpetuate the illusory separation of the two nor to force a false unity between them. As for false unities, Horkheimer has in mind both crude materialist theories that reduce "spirit" to operations of matter as well as idealistic theories that reduce the material world to a manifestation of "spirit." In either case, both theoretical approaches remain trapped 
within the logic of identity, since they are equally driven by the metaphysical impulse to dominate nature in that they attempt to reduce the one to the other and perpetuate the domination of humanity.

Consequently, for Horkheimer, reconciling the antagonism between reason and nature requires dispensing with not only metaphysics and its logic of identity but also the very impulse to dominate nature that gives rise to metaphysics. Moving toward a solution, he claims:

Reason can realize its reasonableness only through reflecting on the disease of the world as produced and reproduced by man; in such self-critique, reason will at the same time remain faithful to itself, by preserving and applying for no ulterior motive the principle of truth that we owe to reason alone. The subjugation of nature will revert to subjugation of man, and vice versa, as long as man does not understand his own reason and the basic process by which he has created and is maintaining the antagonism that is about to destroy him. Reason can be more than nature only through concretely realizing its "naturalness"- - which consists in its trend to domination - the very trend that paradoxically alienates it from nature. Thus also, by being the instrument of reconciliation, it will be more than an instrument. $(E R, 177)^{30}$

In effect, Horkheimer claims that to overcome the crisis of reason that he has diagnosed, reason must recognize its own "naturalness"- the impulse to domination - at work in its construction of the dualism between the abstract ego and nature $(E R, 177)$. In this way, if the impulse to dominate nature is at the heart of reason's invention of an abstract ego that stands outside and above nature-as the corrupting impulses that would contaminate absolute knowledge of transhistorical truths reflecting the structure of nature-then reason must recognize its origin in and relation to nature to check this impulse. Once reason recognizes the metaphysical impulse as a manifestation of the will to dominate nature - and that the metaphysical impulse is itself a manifestation of nature-it can begin to formulate a nonmetaphysical understanding of nature that neither reinscribes the dualism between reason and nature nor reduces the one to the other but that is instead adequate to the complex interrelation between them.

Abandoning metaphysics and the logic of identity as possible correctives to the current forms of domination and oppression, since they are born from the will to dominate, Horkheimer envisions as an alternative task for philosophy

30. Horkheimer defines the principle of truth, to which he appeals a few pages later, as "the adequation of name and thing" (ER, 180). 
the process of a twofold negation. First, philosophy should expose the historical relativity of metaphysical systems that present their principles as ultimate and eternal truths. And second, it should measure a culture's basic ideas and values against the social reality to which they belong so as to assess the breach between them. While ideals such as justice, equality, and freedom are evacuated of their timeless metaphysical content, philosophy can gauge the dissonance operative between social reality and the ideals that a culture professes to valorize in order to close the distance between them. Philosophy, through negation, can not only remove impediments to the development of humanity, which is, for Horkheimer, a step toward a more robust freedom and individuality for humanity, but also act as a corrective to history and, in his own words, "help to keep the course of humanity from resembling the meaningless round of the asylum inmate's recreation hour" $(E R, 186)$.

\section{A Crisis of Critique in Horkheimer's Eclipse of Reason}

Sympathetic with Horkheimer's analyses, Lohmann is explicit that Horkheimer's intent to locate the "negativity of instrumental reason" in the "phenomena of failed self-realization" remains significant for understanding and appreciating the impetus to engage in a critique of instrumental reason at all. Yet, even though this critical intent is worth preserving, Horkheimer's critique itself runs aground in irresolvable contradictions for Lohmann. Lohmann claims that "since it could not develop another, positive concept of reason, the critique of instrumental reason could not be certain of its own activity and, in the end, became entangled in ambiguities and aporetic justifications" (FSR, 388). In reconstructing the central argument of Horkheimer's text, Lohmann emphasizes that Horkheimer's analysis of the crisis of reason undermines any foundational position from which one could indict or resist the collapse of reason. On Lohmann's account, Horkheimer's critique of reason either remains merely at the level of the programmatic or succumbs to historical relativism, since it fails to secure an adequate foundation for critique. In Lohmann's own terms, Horkheimer's analysis needs a "comprehensive concept of reason" through which the critique of reason can be justified. However, since Horkheimer's history of the crisis of reason tells the story of the rise of subjective reason as calculating instrumentality-and its overthrow of an objective form of reason that could secure metaphysical foundations - critique therein loses any basis on which to rest truth claims, which Lohmann regards as essential for any project of critique. Thus Horkheimer's critique of subjective reason must be relativistic, since, on his own admission, there is no form of absolute reason to which he can appeal. For this reason, Lohmann claims that "the 
demonstration that the instrumental reason of subjective self-preservation ultimately destroys the individual whose self-realization it originally aimed to promote is . . . denunciatory. Yet this finding yields no objectively justifiable alternative. It shows only that these approaches do not work" (FSR, 406). In the end, according to Lohmann, Horkheimer is left only with a vague appeal to a form of reason that is "other" to the one born of the metaphysical impulse to dominate nature and not a substantial basis on which to decry philosophically the instrumentalization of reason. To this extent, Lohmann's analysis of the critique of instrumental reason in Eclipse of Reason charges Horkheimer with engaging in a totalizing critique of reason that undermines its own foundations and falls prey to contradiction.

Lohmann's reading of Eclipse of Reason, however, rests entirely on an understanding of critique in its metaphysical form-whereby false absolutes are unmasked via an appeal to a foundational truth, and practices that deviate from an understanding of that truth are denounced as aberrant, immoral, and unjust. Employing this conception of critique, Lohmann cannot help but find Horkheimer's text enigmatic. As Lohmann sees it, Horkheimer's analysis of instrumental reason purports to trace the destruction of any position from which one could launch critique, yet somehow presses forward in the very attempt to critique this situation. For Lohmann, Horkheimer's Eclipse of Reason is at best nonsensical and at worst rife with contradiction. Based on this understanding of critique, Lohmann deems a "programmatic" reading of Horkheimer's critique untenable, since such a reading cannot secure the validity of its claims and hence lacks any "force" or "bite" in its analyses. Yet Horkheimer's interdisciplinary materialism, as shown above, was distinctly programmatic in this way. As an avowed methodological alternative to metaphysical philosophy, it is an explicit tenet of an interdisciplinary materialism that the aim of alleviating human suffering is an end that requires no further justification and that an interdisciplinary materialism itself serves only as a dialectical approach to historically specific cultural constructions. For this reason, an interdisciplinary materialism stands as an exemplary postmetaphysical philosophy, since its ends and approach are not purported to reflect a transhistorical understanding of the ultimate nature of reality but are instead operating principles of inquiry and action resulting from a considered methodological decision-in other words, neither purport to reflect timeless, universal truths. Thus Lohmann's indictment of Horkheimer's critique of instrumental reason for its possible programmatic nature is not in and of itself a refutation of it. ${ }^{31}$

31. Or one might say that the "programmatic" nature of a theory could be regarded as its refutation only by those who presuppose metaphysics to be the sole proper method for philosophy and critique. 
To the contrary, its programmatic nature is precisely what is most laudable in Horkheimer's elaboration of an interdisciplinary materialism as a postmetaphysical methodology.

If Horkheimer's critique of instrumental reason were elaborated programmatically in the same manner as his interdisciplinary materialism, this would, despite Lohmann's claims to the contrary, be a real boon for his analyses. However, Lohmann's sense that Horkheimer's critique of instrumental reason presents something more than just a programmatic analysis, that a metaphysical specter looms at its core, is not entirely unfounded. Indeed, Horkheimer is not content simply to denounce the effects of instrumentalized reason: he grounds his critique in the failures of reason itself. Thus we find Horkheimer condemning reason not just for its undesirable outcomes in the forms of instrumentalized reason and the liquidation of the self but also for the very form of subjectivity to which it gives rise-namely, an abstract ego that exists as the site of reason and in an antagonistic relation to nature. Central to Horkheimer's analysis of the crisis of reason is the position that the antagonism between the abstract ego and nature is a false dichotomy. Unifying myth, metaphysics, and science is the impulse to dominate nature, and it is here, in the impulse to dominate nature, that Horkheimer locates reason's invention of the division between the abstract ego, as the knowing subject, over and against nature as what is to be conceptualized and schematized for the purposes of being controlled. Rejecting the metaphysics of the abstract ego as the site of an illusion, Horkheimer claims that "the formalistic method of definition proves particularly inadequate when applied to the concept of nature. For to define nature and its complement, spirit, is inevitably to pose either their dualism or their unity, and to pose the one or the other as an ultimate, a 'fact,' while in truth these two fundamental philosophical categories are inextricably interconnected" $(E R, 169)$. Moreover, if at the core of abstract conceptualizations is the logic of identity - the metaphysical ideal of all-embracing and totalizing epistemic conceptualizations that achieve a perfect equivalence between concept and object, and which presuppose the existence of transhistorical unities that exist independently of the historical contingencies of space and time as well as a knowing subject that can overcome those contingencies to access them-then, according to Horkheimer, we need to effect a reconciliation between reason and nature via a new form of nonidentity thinking, one that no longer perpetuates the illusory separation of reason and nature due to its impulse to dominate nature.

However, if we recall Horkheimer's earlier objections to metaphysics, he precisely denounced metaphysics as a political instrument for imposing particular interests on other groups under the guise of a binding universality. As a postmetaphysical thinker, Horkheimer would explicitly reject the very form of critique that Lohmann brings to bear on him. 
In essence, by tracing our modern form of scientific thinking back to its historical origins, Horkheimer claims to have disclosed the aberrant moment in history, in thinking, at which reason derailed from its emancipatory potentialnamely, at the moment of a corrupting invention that falsely created a division between the abstract ego and nature as its antagonist. In this way, in Eclipse of Reason, Horkheimer can confidently advocate nonidentity thinking as the corrective to our modern barbarism - which is only intimated at in Dialectic of Enlightenment. However, as Lohmann points out, if this is the case, "then the denunciatory version of the self-criticism of reason has . . passed over into the attempt to recover a comprehensive concept of reason." So "the 'basic difference between the ideal and the real' characteristic of this 'true philosophy' is at the same time a relapse into metaphysics" (FSR, 407). For Lohmann, Horkheimer's appeal to a foundational conception of truth, and thus a comprehensive concept of reason, means that Horkheimer is squarely engaged in metaphysics. However, for Lohmann, this leaves Horkheimer in an irresolvable contradiction, since, in regard to metaphysics, he states explicitly that "the classical systems of objective reason, such as Platonism, seem to be untenable because they are glorifications of an inexorable order of the universe and therefore mythological" $(E R, 180)$. In other words, Horkheimer appears both to reject metaphysics and to appeal to a foundational conception of truth that has metaphysical implications, and thus runs aground in aporia.

Horkheimer's position is, however, more nuanced than Lohmann presents it. The tension at work in Horkheimer's critique is not a blatant contradiction but a category mistake. Since Horkheimer narrowly equates metaphysics with identity thinking, he considers a disclosure of the nonidentical at the heart of a more authentic reason to be something "other" than metaphysics. However, even though the open and nontotalizing character of nonidentity thinking is, on the surface, different from the closed and total character of identity thinking, it serves in Horkheimer's final thought the very same function he had earlier in his career attributed to metaphysical philosophy-namely, as an insight into the transhistorical, universal, and essential structure of reality on which to establish the normative foundations for one's life, even if in this case the insight reveals nonidentity rather than identity. Here, we can delineate the difference between identity and nonidentity thinking in the difference between what I would term centripetal and centrifugal metaphysics. Whereas a centripetal metaphysics, which Horkheimer rejects, would aim to wash away historical contingency and difference to reveal an indissoluble identity that would in some way return us to the privileged perspective of a metaphysical center, a centrifugal metaphysics would alternatively aim to disclose the fundamentally 
contingent nature of history and "unmask" all metaphysical identities as false in the name of a noncenter that continually displaces and fractures. Thus Horkheimer's critique of instrumental reason does not explicitly contradict itself, as Lohmann claims; rather, it erects an antimetaphysics grounded in the transhistorical truth of nonidentity, which is, in the end, just another metaphysics, but in this case a metaphysics of nonidentity.

That nonidentity thinking now serves as the noncenter in a centrifugal metaphysics for Horkheimer is revealed both in his characterization of identity thinking and in his claims about the new tasks of philosophy. Because Horkheimer considers nonidentity true-or rather, because it comes to serve as a transhistorical absolute- he falls into designating identity thinking as false, the division between the abstract ego and nature as the site of an illusion, and the forms of domination at work in the twentieth century as the result of an error that can be corrected only by returning to the truth, that is, to nonidentity thinking. Horkheimer's critique of instrumental reason, as it is elaborated in Eclipse of Reason, comes to function in the exact same manner as the form of metaphysical critique he had earlier rejected under the banner of an interdisciplinary materialism, since he makes the perilous move to ground absolutely his critique of instrumental reason in the transhistorical truth of nonidentity thinking, and on this basis to denounce instrumental reason as an aberration and its consequences for humanity as barbarous. Thus we find Horkheimer moving beyond a merely "programmatic" critique of instrumental reason and instead attempting to establish the legitimacy of his critique by resting it on a metaphysical foundation. One might say, quite simply, that Horkheimer's critique reconstructed the dogmatic philosophy of history and theoretical ossification that he had early on sought to avoid. Consequently, the only tasks of which Horkheimer can conceive for his new centrifugal metaphysics are merely destructive and negative. Besides maintaining the now vague hope of alleviating the suffering of individuals in contemporary society, Horkheimer can envision no greater aims than dismantling all false absolutes and persevering in the vigilance against advancing any himself — what ultimately amounts to a totalizing, pessimistic philosophy. In the end, Horkheimer managed to fashion one more transhistorical absolute - an empty center into which nothing is to be placed-in the attempt to undermine all absolutes, and for this reason succeeded in reestablishing what he had fought his entire life to avoid: the tyranny of dogmatic metaphysics. But, in this case, it is the tyranny of an antimetaphysics committed to uprooting every identity in the name of the nonidentical at the heart of reason.

Ultimately, Lohmann's sense that a metaphysical tone is at work in Horkheimer's critique of instrumental reason is correct. However, as I have 
demonstrated, the situation is more nuanced, and even more significant, than Lohmann presents it. The tone should be characterized more accurately as antimetaphysical than metaphysical. The significance of this difference is worth noting, since it brings into relief the perils that lie in wait for any critique of metaphysics that aims to secure absolutely its own foundation. Positions that bring the metaphysical form of critique to bear on metaphysics in an attempt to refute metaphysics establish themselves as antimetaphysical positions, and in doing so-in bringing the tools of metaphysics to bear on metaphysics - transmogrify into variants of metaphysics, since, like metaphysics, they attempt to procure the certainty of their own critiques at the cost of declaring the universal and transhistorical certainty of their own position, which generally functions to sanction the exclusion of any position that dissents from its own. And, as discussed above, it was this element of metaphysics to which Horkheimer most objected as a form of domination-that is, he thought metaphysics served as an instrument of coercion. Yet, despite his awareness of the dominating tendencies lurking in metaphysics and his objection to it, Horkheimer's later critique of instrumental reason veers into establishing an antimetaphysical position, since it elaborates a transhistorical form of nonidentity thinking as the legitimate basis on which to justify its indictment of identity thinking and metaphysics, which mires him in the totalizing, dominating, and oppressive forms of thought that he sought to obviate. In other words, Horkheimer's "re-philosophizing" of his interdisciplinary materialism through the construction of a transhistorical concept of nonidentity thinking reshapes his once open dialectic into another closed and totalizing system. ${ }^{32}$ However, this turn to an antimetaphysics in his later work calls attention to how significant Horkheimer's earlier work elaborating an interdisciplinary materialism is for pointing the way forward for developing viable postmetaphysical philosophies that stand as genuine alternatives to metaphysics rather than as antimetaphysical positions that stumble into the pitfall of becoming refutations of metaphysics.

\section{Conclusion}

Early in his career Horkheimer was vigilant in casting his interdisciplinary materialism as a methodological alternative to metaphysical philosophy that, importantly, evades the equally perilous absurdities of academic skepticism and relativ-

32. See Dubiel, Theory and Politics, 103-7. I would like to thank the reviewer for drawing my attention to this specific characterization of the Frankfurt School's work in the late 1930s and the 1940s by Dubiel. 
ism. This was all the more impressively demonstrated in Horkheimer's refusal to provide a metaphysical foundation for the normative orientation of his interdisciplinary materialism, especially given the overwhelmingly powerful impetus one experiences in wanting to do so. One of the single greatest contributions of Horkheimer's work to critical social theory is the rigor and sophistication with which he demonstrated that his interdisciplinary materialism as a postmetaphysical philosophy can serve as a coherent method for addressing the sociopolitical issues of our time. His emphasis on alternative forms of thought and subjectivity, as well as alternative ways of relating to others and the world, still stand as significant ideals for our time. Horkheimer's work developing a viable postmetaphysical critical social theory offers a considerable theoretical resource for those looking to engage in philosophy outside the bounds of metaphysics.

George W. Shea, IV is assistant professor of philosophy at Misericordia University.

\section{References}

Abromeit, John. Max Horkheimer and the Foundations of the Frankfurt School. Cambridge: Cambridge University Press, 2011.

Benhabib, Seyla, Wolfgang Bonß, and John McCole, eds. On Max Horkheimer: New Perspectives. Cambridge, MA: MIT Press, 1993.

Berendzen, J. C. "Postmetaphysical Thinking or Refusal of Thought? Max Horkheimer's Materialism as Philosophical Stance." International Journal of Philosophical Studies 16, no. 5 (2008): 695-718.

Brunkhorst, Hauke. "Dialectical Positivism of Happiness: Max Horkheimer's Materialist Destruction of Philosophy." In Benhabib, Bonß, and McCole, On Max Horkheimer, 67-98.

Buck-Morss, Susan. The Origin of Negative Dialectics: Theodor W. Adorno, Walter Benjamin, and the Frankfurt School. New York: Free Press, 1977.

Dubiel, Helmut. Theory and Politics: Studies in the Development of Critical Theory, translated by Benjamin Gregg. Cambridge, MA: MIT Press, 1985.

Foucault, Michel. Birth of the Clinic: An Archaeology of Medical Perception, translated by A. M. Sheridan. New York: Pantheon, 1973.

Foucault, Michel. History of Madness, edited by Jean Khalfa, translated by Jonathan Murphy and Jean Khalfa. Oxon: Routledge, 2006.

Foucault, Michel. The Order of Things: An Archaeology of the Human Sciences, translated by A. M. Sheridan Smith. New York: Pantheon, 1994.

Habermas, Jürgen. The Philosophical Discourse of Modernity, translated by Frederick Lawrence. Cambridge, MA: MIT Press, 1987. 
Hegel, G. W. F. Phenomenology of Spirit, translated by A. V. Miller. Oxford: Oxford University Press, 1977.

Horkheimer, Max. "Beginnings of the Bourgeois Philosophy of History.” In Between Philosophy and Social Science: Selected Early Writings, translated by G. Frederick Hunter, Matthew S. Kramer, and John Torpey, 313-88. Cambridge, MA: MIT Press, 1995.

Horkheimer, Max. Dämmerung, partly translated as “Dawn: Notes 1926-1931." In Dawn and Decline: Notes, 1926-1931 and 1950-1969, translated by Michael Shaw, 15-112. New York: Seabury, 1978.

Horkheimer, Max. Eclipse of Reason. London: Continuum, 2004.

Horkheimer, Max. "The Future of Marriage." In Critique of Instrumental Reason: Lectures and Essays since the End of World War II, translated by Matthew J. O'Connell et al., 84-100. New York: Continuum, 1985.

Horkheimer, Max. "Materialism and Metaphysics." In Critical Theory: Selected Essays, translated by Matthew J. O'Connell et al., 10-46. New York: Continuum, 1999.

Horkheimer, Max. "Materialism and Morality.” In Between Philosophy and Social Science: Selected Early Writings, translated by G. Frederick Hunter, Matthew S. Kramer, and John Torpey, 15-47. Cambridge, MA: MIT Press, 1995.

Horkheimer, Max. "On the Problem of Truth.” In Between Philosophy and Social Science: Selected Early Writings, translated by G. Frederick Hunter, Matthew S. Kramer, and John Torpey, 177-216. Cambridge, MA: MIT Press, 1995.

Horkheimer, Max. "The Present Situation of Social Philosophy and the Tasks of an Institute for Social Research.” In Between Philosophy and Social Science: Selected Early Writings, translated by G. Frederick Hunter, Matthew S. Kramer, and John Torpey, 1-14. Cambridge, MA: MIT Press, 1995.

Horkheimer, Max. "The Rationalism Debate in Contemporary Philosophy." In Between Philosophy and Social Science: Selected Early Writings, translated by G. Frederick Hunter, Matthew S. Kramer, and John Torpey, 217-64. Cambridge, MA: MIT Press, 1995.

Horkheimer, Max. "Threats to Freedom.” In Critique of Instrumental Reason: Lectures and Essays since the End of World War II, translated by Matthew J. O'Connell et al., 136-58. New York: Continuum, 1985.

Horkheimer, Max. "Tradition and Critical Theory.” In Critical Theory: Selected Essays, translated by Matthew J. O'Connell et al., 188-243. New York: Continuum, 1999.

Horkheimer, Max, and Theodor Adorno. Dialectic of Enlightenment: Philosophical Fragments, translated by Edmund Jephcott. Stanford, CA: Stanford University Press, 2002.

Jay, Martin. The Dialectical Imagination: A History of the Frankfurt School and the Institute of Social Research, 1923-1950. Berkeley: University of California Press, 1996.

Jay, Martin. Permanent Exiles: Essays on the Intellectual Migration from Germany to America. New York: Columbia University Press, 1986.

Jay, Martin. Reason after Its Eclipse: On Late Critical Theory. Madison: University of Wisconsin Press, 2016.

Jefferies, Stuart. Grand Hotel Abyss: The Lives of the Frankfurt School. London: Verso, 2017. 
Kuhn, Thomas S. The Structure of Scientific Revolutions. Chicago: University of Chicago Press, 1996.

Lohmann, Georg. "The Failure of Self-Realization: An Interpretation of Horkheimer's Eclipse of Reason.” In Benhabib, Bonß, and McCole, On Max Horkheimer, 387-412.

Stirk, Peter M. R. Max Horkheimer: A New Interpretation. Hertfordshire: Harvester Wheatsheaf, 1992.

Wiggershaus, Rolf. The Frankfurt School: Its History, Theories, and Political Significance, translated by Michael Robertson. Cambridge, MA: MIT Press, 1994. 